This document is the Accepted Manuscript version of a Published Work that appeared in final form in Journal of Materials Chemistry A 8(10) : 5350-5362 (2020), copyright ( 2020 The Royal Society of Chemistry. To access the final edited and published work see https://doi.org/10.1039/C9TA12827A

\title{
The influence of interfacial interactions on the conductivity and phase behaviour of organic ionic plastic crystal/polymer nanoparticle composite electrolytes
}

\author{
Frederick Nti, ${ }^{a}$ Luca Porcarelli, ${ }^{a, b}$ George W. Greene, ${ }^{a}$ Haijin Zhu, ${ }^{a}$ Faezeh Makhlooghiazad, ${ }^{a}$ \\ David Mecerreyes, ${ }^{b}$ Patrick C. Howlett, ${ }^{a}$ Maria Forsyth ${ }^{\mathrm{a}, \mathrm{b}}$, Xiaoen Wang ${ }^{\star a}$
}

\begin{abstract}
alnstitute for Frontier Materials, Deakin University, Geelong, VIC 3217, Australia bPOLYMAT, University of the Basque Country UPV/EHU, Joxe Mari Korta Center, Avda. Tolosa 72, 20018 Donostia-San Sebastian, Spain
\end{abstract}

Email: xiaoen.wang@deakin.edu.au

\begin{abstract}
Organic ionic plastic crystals (OIPCs) have been recognised as promising solid-state electrolyte materials for next-generation energy storage devices. Recently, the addition of polymer nanofillers to OIPCs has led to the design of OIPC-based solid-state electrolytes with enhanced mechanical stability and ion conductivity. However, the mechanisms of enhancement and the influence of different polymer surface chemistries on the ion dynamics are not yet well understood, which has hindered the further development of high-performance OIPC-based electrolytes. In this work, we selected two different polymer nanoparticles, poly(vinylidene fluoride) (PVDF) and polystyrene (PS), and investigated the effects of the polymer surfaces on the thermal behaviour and ion transport properties of the OIPC, $N$-ethyl $\mathrm{N}$-methyl pyrrolidinium bis(fluorosulfonyl)imide ([ $\left.\left.\mathrm{C}_{2} \mathrm{mpyr}\right][\mathrm{FSI}]\right)$. We found significantly different interfacial structures, as well as ion transport behaviours in the OIPC/nanoparticle composites. Specifically, compared with pure $\left[\mathrm{C}_{2} \mathrm{mpyr}\right][\mathrm{FSI}]$, the addition of PVDF nanoparticles effectively enhanced the ion conductivity of the OIPC composite, with the optimum achieved near the percolation threshold of PVDF nanoparticles.

In contrast, the addition of PS nanoparticles to the OIPC led to a slight enhancement at low concentrations and then a significant decrease in conductivity at higher concentrations. DSC, FTIR and EIS confirm that the interaction between the PVDF nanoparticles and the OIPC induces the formation of less ordered OIPC layers on the PVDF surfaces, leading to the conductivity enhancement. Finally, different structure models based on the results of this work are proposed, which provide principle guidelines for the design of future OIPC-based highly conductive electrolyte materials.
\end{abstract}


A careful look at the various industrial revolutions begs the realisation that energy is the driving force for further development. It is no surprise that the faster-developing countries account for the highest pollution. Most of the world's present energy needs are met by burning fossil fuels, which results in the release of vast amounts of carbon dioxide and carbon monoxide into the atmosphere. Thus it is crucial to switch from fossil fuel dependency to renewable energy dependency. ${ }^{1}$ The surge in demand for renewable energy systems requires effort geared towards improving energy generation, and storage systems such as dye synthesised solar cells, batteries, fuel cells and supercapacitors. ${ }^{2}$ Most of these systems require an electrolyte, which serves as a medium for ion conduction for their operation. It is, therefore, vital to study electrolyte systems and to tune their performance to support these technologies.

Organic ionic plastic crystals (OIPCs) are a promising new class of electrolyte material due to their inherent advantages. Importantly, they have the capacity to overcome the problem of electrode volume change during battery charge-discharge cycling due to their plastic properties. Being non-flammable and non-volatile, owing to the columbic interactions between their charged species, they are attractive as solid-state electrolytes that can serve as safer alternatives to liquid electrolytes. Having high thermal stability, inherent attractive material properties and demonstrating the potential for improved target ion conduction, OIPCs are considered as one of the most promising solid electrolytes. $3,4,5,6$

Plastic crystals disorder in a staged-like manner with increasing temperature. The highest temperature right before the melt phase is denoted as phase $\mathrm{I}$ and the subsequent temperature phases are denoted as phases II, III, IV, etc. ${ }^{7}$ A small enthalpy of fusion typically characterises them since their most conductive solid-state phase (phase I) is close to their melt phases. ${ }^{8}$ Their ability to deform under external pressure denotes their plastic properties, which has earned them the name 'plastic crystals'. Their plastic behaviour is desirable for practical device applications because it improves the contact between electrodes and electrolyte. ${ }^{9}$ Even in the deformed state, they exhibit long-range order while maintaining shortrange disorder. It is this short-range disorder that allows for translational and rotational motions of their molecules, leading to potentially high conductivities. ${ }^{10}$ When mixed with an alkali metal salt (i.e., Li or Na), OIPCs have been shown to exhibit dramatic increases in conductivity. ${ }^{11}$ They subsequently have demonstrated sufficient target ion transport and electrochemical stability to support charge transfer in $\mathrm{Li}^{5,12,13}$ and $\mathrm{Na}^{14,15}$ cells.

Despite the promise of high performance and the potential to replace liquid electrolytes, most OIPCs are soft and easily deformed under pressure, making it challenging to form freestanding membranes out of these materials. Different materials such as polymer nanoparticles 
and polymer nanofibres have been added to these soft OIPC matrices in order to achieve selfstanding membranes with improved mechanical properties. Unexpectedly, some of these composites showed not only improved mechanical properties but also higher ion conductivity. ${ }^{16,17}$

Yoshizawa-Fujita et al. were the first to synthesise and characterise $N$-ethyl, $N$-methyl pyrrolidinium bis(fluorosulfonyl)imide, $\left[\mathrm{C}_{2} \mathrm{mpyr}\right][\mathrm{FSI}]$, which has a room temperature ionic conductivity of $1.23 \times 10^{-6} \mathrm{~S} \mathrm{~cm}^{-1}$. The OIPC starts melting at $205^{\circ} \mathrm{C}$ and shows plastic behaviour over a temperature range of $-22{ }^{\circ} \mathrm{C}$ to $205{ }^{\circ} \mathrm{C}$, making it desirable for practical electrochemical device applications. Two solid-solid phase transitions are observed in the DSC thermogram before the melt of the OIPC. A high enthalpy change is observed for the transition from phase III to phase II, and a small enthalpy change is recorded from phase II to phase I. Unlike similar plastic crystals with high conductivities, the entropy of fusion (11 JK${ }^{1} \mathrm{~mol}^{-1}$ ) observed for $\left[\mathrm{C}_{2} \mathrm{mpyr}\right][\mathrm{FSI}]$ is consistent with Timmerman's criterion suggesting that $\left[\mathrm{C}_{2}\right.$ mpyr][FSI] has plastic crystalline properties. With the help of TG-DTA, it was determined that thermal decomposition and melting of $\left[\mathrm{C}_{2} \mathrm{mpyr}\right][\mathrm{FSI}]$ starts simultaneously since weight loss starts at $200{ }^{\circ} \mathrm{C}$ and melting at $205^{\circ} \mathrm{C} . .^{18}$

In earlier work, the effect of PVDF nanofibers on Li-doped [ $\left.\mathrm{C}_{2} \mathrm{mpyr}\right][\mathrm{FSI}]$ was studied in a lithium battery system. The composite material showed improved ionic conductivity compared to the neat material and could support cycling at $0.13 \mathrm{~mA} \mathrm{~cm}^{-2}$ at both room temperature and at $50{ }^{\circ} \mathrm{C}$ for over 500 cycles. ${ }^{19}$ Wang et al. also employed a coating and pressing method to form a dense composite material containing a higher content of PVDF particles compared to the Li-doped $\left[\mathrm{C}_{2} \mathrm{mpyr}\right][\mathrm{FSI}]$. This method allows for accurate control of the OIPC/PVDF composition, which enables analysis of the interfacial effects as well as analysis of the thickness of the OIPC layer on PVDF surfaces. It was shown that the low content of OIPC ( $40 \mathrm{wt} \%$ ) could improve ion conductivity by an order of magnitude. This work also presented a way to design cost-effective, high-performance composite electrolytes by using less OIPC and more PVDF, achieving high transference number (0.44) and excellent Li|NMC solid-state cell performance $\left(1300\right.$ cycles at $\left.50{ }^{\circ} \mathrm{C}\right) .{ }^{17}$ It has been proposed that an interfacial layer with a high increased defect concentration is formed on the surface of some polymer nanoparticles and nanofibres when they interact with certain OIPCs. ${ }^{16,20}$ This accounts for their improved properties, yet there is no literature dedicated to explain the effect and nature of this interfacial layer formed between OIPC/polymer composites.

In other instances, however, OIPCs and polymer interactions have resulted in reduced ionic conductivity and improved ordering of the OIPC matrix. ${ }^{21}$ For instance, Rao et al. studied the effect of electrospun PVDF nanofibers on 1-( $N, N$-dimethylammonium)-2-(ammonio)ethane 
triflate ([DMEDAH $\left.\left.]_{2}\right][T]_{2}\right)$ protic OIPC (POIPC). Unlike other studies, they recorded a significant decrease in ionic conductivity. DSC results suggested that the addition of PVDF improved the ordering of the POIPC. The DSC results were confirmed by NMR analysis, which showed that the composite membranes had a reduced mobile component as a result of the improved ordering. This observation was attributed to a reduction of the mobile phase of the charge carriers when PVDF nanofibers were added to the POIPC. ${ }^{22}$

It is not yet fully understood why some OIPC-polymer interactions result in enhanced ionic conductivity, where others have the opposite effect. Such a fundamental understanding is the goal of this study. This work presents a study of the effect of two polymers, poly(vinylidene fluoride) (PVDF)and polystyrene (PS), on the phase behavior, crystal structure and ion dynamics of $\left[\mathrm{C}_{2} \mathrm{mpyr}\right][\mathrm{FSI}$. This OIPC is chosen for its attractive properties and previous reports of application in Li based solid-state batteries, it was studied without Li salt addition to form a basic understanding of the role of the OIPC cation and anion structure in the enhancement of ion transport. Future studies will continue to examine more complex OIPC composite systems with lithium and sodium salt addition.

\section{$2 \quad$ Experimental}

\subsection{Materials and sample preparation}

A previously established procedure was used to synthesise $\left[\mathrm{C}_{2} \mathrm{mpyr}\right][\mathrm{FSI}]{ }^{18,23}$ PVDF nanoparticles with diameter an average diameter of $360 \mathrm{~nm}\left(\mathrm{KF} 850, \mathrm{M}_{\mathrm{w}}=3 \times 10^{5}\right.$, Kureha Chemicals, Japan) were dried $80^{\circ} \mathrm{C}$ for two days at in a vacuum oven before being used. Methanol (>99\%, Sigma-Aldrich) was used as received.

\subsection{Synthesis of PS nanoparticles}

PS nanoparticles were synthesised in a $250 \mathrm{~mL}$ three-neck round bottom flask, equipped with a reflux condenser, a nitrogen inlet and a temperature probe. The flask was charged with 100 $\mathrm{mL}$ of Milli-Q water, $0.043 \mathrm{~g}$ of SDS, $0.249 \mathrm{~g}$ of divinylbenzene, and $9.751 \mathrm{~g}$ of styrene. The flask was degassed for 20 minutes with nitrogen, and the temperature was raised to $80{ }^{\circ} \mathrm{C}$. The polymerisation was initiated by the addition of one-shot of $100 \mathrm{mg}$ of $\mathrm{K}_{2} \mathrm{~S}_{2} \mathrm{O}_{8}$ in $2 \mathrm{~mL}$ of water. The reaction proceeded for 2 hours. Then, the PS particle dispersion was filtered with an $80 \mu \mathrm{m}$ nylon mesh to remove polymer coagulum. The gravimetric conversion was higher than $95 \%$. The obtained PS particle dispersion was dialysed against Milli-Q water using Spectra-Por 4 membranes (Mw cut-off 12000-14000 Da) for three days. Estimation of the particle size by DLS yields a number-weighted size of $267 \mathrm{~nm}$ and a narrow polydispersity $(P D I=0.056)$. Finally, the PS particle dispersion was freeze-dried to remove water. In order to ensure that the experiment was not affected by the functionalized PS surface, the particles were washed in excess methanol at $80^{\circ} \mathrm{C}$ to rid the particles of surfactants. 


\subsubsection{Composite preparation}

OIPC/polymer composites were prepared by solution casting. Selected volume fractions were prepared by dispersing calculated amounts of OIPC and polymer nanoparticles in methanol.

The solution was sonicated to distribute the polymer nanoparticles, and OIPC in the methanol uniformly and then stirred to form a uniform suspension. The suspension was cast on a petri dish, and the methanol was quickly evaporated under argon flow. The sample was then collected from the petri dish into an agate mortar and ground to form small uniform particles (to ensure uniform distribution of the nanoparticles in the OIPC matrix). Finally, the sample was transferred into a glass vial and dried on a Schlenk line at $50^{\circ} \mathrm{C}$ for 24 hours to remove all traces of the solvent. The samples were then transferred into an argon-filled glove box for storage and characterization.

\subsection{Characterisation}

In order to investigate the interfacial effects of different polymer nanoparticles on OIPC behaviours, $\left[\mathrm{C}_{2} \mathrm{mpyr}\right][\mathrm{FSI}] / \mathrm{PVDF}$ and $\left[\mathrm{C}_{2} \mathrm{mpyr}\right][\mathrm{FSI}] / \mathrm{PS}$ composites with different nanoparticle volume fractions are characterized, the characterisation techniques such as differential scanning calorimetry (DSC), electrochemical impedance spectroscopy (EIS), nuclear magnetic resonance (NMR), scanning electron microscopy (SEM) and Fourier-transform infrared (FTIR) spectroscopy are used.

Changes in the phase behaviour of the OIPC with respect to the volume fraction of polymer nanoparticles were studied using differential scanning calorimetry (DSC). The thermal analysis was carried out using a Mettler Toledo DSC1 instrument, which runs on a STAReV6.10 software. The samples were prepared for DSC measurements by sealing $4-8$ mg of sample in an Al pan inside a glovebox under an Ar atmosphere. In order to avoid the influence of thermal history of the samples, three thermal cycles were performed for each sample with heat flow regulated to a rate of $2^{\circ} \mathrm{C} / \mathrm{min}$ for all the samples. All samples were held at an isothermal temperature of $-110^{\circ} \mathrm{C}$ for 30 mins before heating. For the first cycle, the sample was heated to $50^{\circ} \mathrm{C}$, the second to $100^{\circ} \mathrm{C}$ and the third to $220^{\circ} \mathrm{C}$. The DSC scans presented herein were normalised based on the mass of plastic crystal in the respective composite sample.

Ionic conductivities of the samples were measured on a Biologic MTZ-35, which runs on an MT-lab software. Dried samples were pressed between two stainless steel disks in a sealed $\mathrm{KBr}$ die under 4 tons of pressure for 10 minutes. Each pellet, which was sandwiched between two stainless steel discs, was sealed in a coin cell and inserted into a hermetically-sealed barrel cell. ${ }^{24} \mathrm{~A}$ frequency range of $10 \mathrm{MHz}$ to $1 \mathrm{~Hz}$ was studied using a voltage amplitude of 
$0.01 \mathrm{~V}$ with temperature ranging from $30{ }^{\circ} \mathrm{C}$ to $120{ }^{\circ} \mathrm{C}$ at $10^{\circ} \mathrm{C}$ steps. The system was equilibrated for 20 minutes at each target temperature before each measurement was taken. The value at which the semi-circle, obtained from the Nyquist plot, touched the $x$-axis at the high-frequency region was taken as the resistance of the samples.

The mobility of ionic species was probed through variable temperature (VT) solid-state nuclear magnetic resonance spectroscopy (NMR). The samples were packed into $2.5 \mathrm{~mm}$ zirconia MAS rotors in a glove box. The packed rotors were inserted a Bruker AVANCE III $500 \mathrm{MHz}$ wide-bore solid-state spectrometer.

The packing organisation of the particles in the OIPC matrix was studied by analysis of SEM micrographs. The micrographs were acquired on a JEOL JSM-IT300 at an accelerating voltage of $5 \mathrm{kV}$. The samples were pressed into pellets in a $\mathrm{KBr}$ die under 4 tons of pressure for 10 minutes and mounted on SEM stage with carbon tape. The samples were goldsputtered to eliminate charging effects during image acquisition.

The vibrational spectral features of the materials were obtained from attenuated total reflectance Fourier transform infrared (ATR-FTIR) spectroscopy using a single diamond Attenuated Total Reflection (ATR) unit (PerkinElmer) and running on Spectrum software. The spectra were collected from $4000 \mathrm{~cm}^{-1}$ to $650 \mathrm{~cm}^{-1}$ in a controlled atmosphere to minimise the influence of moisture (only the relevant regions of the spectra have been presented herein, in order to highlight the important changes that occurred on the addition of the secondary components). Approximately $10 \mathrm{mg}$ of the solid samples were placed on the sensing surface of the spectrometer and pressure applied to ensure that there was sufficient contact before each spectrum was acquired at a spectral resolution of $4 \mathrm{~cm}^{-1}$ with 32 co-added scans.

\section{$3 \quad$ Results and Discussion}

\subsection{Morphologies of OIPC composites with different polymer particles}

The chemical structures of the OIPC and polymer nanoparticales used in this work are shown in Figure $1 \mathrm{a}$ and $\mathrm{b}$. Figure $1(\mathrm{c}-\mathrm{e})$ shows the SEM images of $\left[\mathrm{C}_{2} \mathrm{mpyr}\right][\mathrm{FSI}] / P V D F$ composites which suggest that PVDF particles are uniformly distributed in the OIPC matrix (the SEM images of all the compositions are shown in Figures S1 and S2). This indicates that PVDF particles have a good affinity for the OIPC matrix. With lower volume fractions of OIPC, the particles are randomly distributed, but at 50 vol\% PVDF and higher, the PVDF nanoparticles appear to be well arranged and closely packed. The population of PVDF nanoparticles does not appear to change much from 50 vol\% and upward, but rather, the content of OIPC in the composite is reduced. Beyond 50 vol\% PVDF, the interaction between the OIPC and PVDF is reduced because of the low volume fraction of OIPC. The packing of the particles with 70 vol\% PVDF nanoparticles (Figure S1 g) shows similar morphology compared with neat PVDF 
nanoparticles because (Figure S1 h) because there is insufficient OIPC and the particles are approaching maximum close packing.

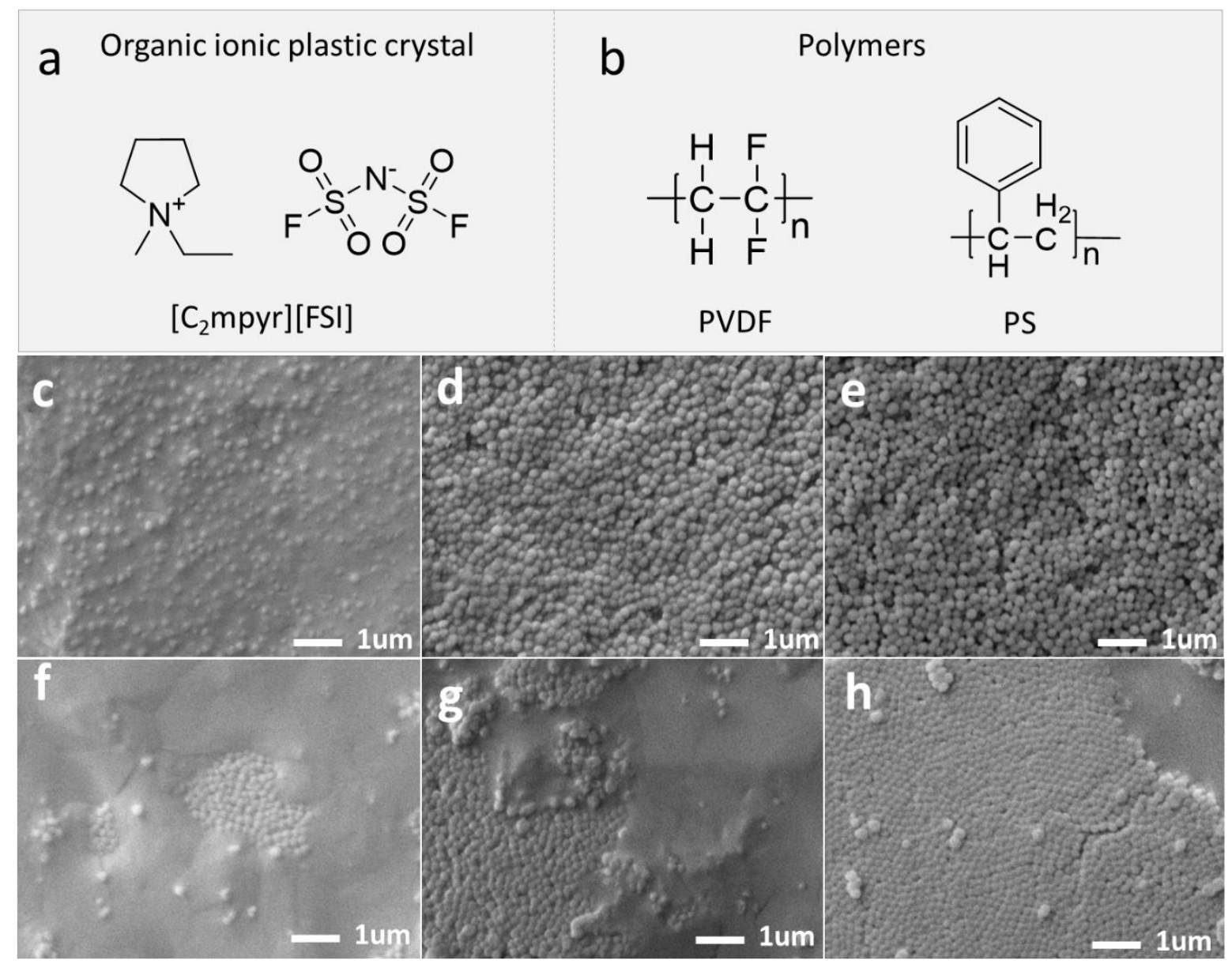

Figure 1: Chemical structures of OIPC (a) and polymer nanoparticles (b); OIPC/nanoparticle composites with different compositions, 70/30 vol\% [ $\left.\mathrm{C}_{2} \mathrm{mpyr}\right][\mathrm{FSI}] / \mathrm{PVDF}$ (c); 50/50 vol\%

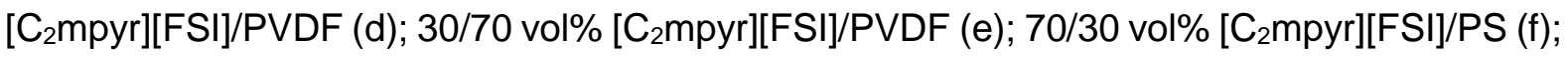
$50 / 50$ vol\% [ $\left.\mathrm{C}_{2} \mathrm{mpry}\right][\mathrm{FSI}] / \mathrm{PS}(\mathrm{g})$ and $30 / 70 \mathrm{vol} \%\left[\mathrm{C}_{2} \mathrm{mpyr}\right][\mathrm{FSI}] / \mathrm{PS}(\mathrm{h})$.

On the other hand, the SEM micrographs of $\left[\mathrm{C}_{2} \mathrm{mpyr}\right][\mathrm{FSI}] / \mathrm{PS}$ composites show that the PS particles have a poor affinity for the OIPC matrix, as shown in Figure $1(f-h)$. The hydrophobic nature of PS leads to efficient packing of the particles, ${ }^{25}$ and the PS particles appear to be clustered together, hence, avoiding interaction with the OIPC matrix. This clustering results from the non-wettable nature of PS. With lower volume fractions of PS nanoparticles, the particles appear to be randomly distributed, which allows for higher interaction as compared 
with the case of higher volume fractions, where the particles are highly clustered together. This creates two separate phases in the composite, one phase made up of conductive OIPC matrix, and the other phase made up of non-conducting PS particles, resulting in increased tortuosity.

\subsection{Thermal behaviours of PVDF composites}

The DSC thermal traces of neat $\left[\mathrm{C}_{2} \mathrm{mpyr}\right][\mathrm{FSI}]$ and the $\left[\mathrm{C}_{2} \mathrm{mpyr}\right][\mathrm{FSI} / \mathrm{PVDF}$ composites containing different volume fractions of PVDF (10 to 90 vol\%) are presented in Figure 2a, with Figures $2 \mathrm{~b}$ and $\mathrm{c}$ highlighting the first and second solid-solid transitions. The DSC results show the new phases formed in the composites with increasing volume fractions of PVDF, evidence of the interfacial interactions occurring in the $\left[\mathrm{C}_{2} \mathrm{mpyr}\right][\mathrm{FSI}] / \mathrm{PVDF}$ composites.

Consistent with previous literature, three significant transitions are observed in the DSC plot of the neat $\left[\mathrm{C}_{2} \mathrm{mpyr}\right][\mathrm{FSI}] .^{18,26}$ The peak located at $-72{ }^{\circ} \mathrm{C}$ corresponds to the first solid-solid transition (phase III to II), the second peak located at $-17^{\circ} \mathrm{C}$ corresponds to the second solidsolid transition (phase II to I), while the third peak located at $204^{\circ} \mathrm{C}$, corresponds to the melt of the $\left[\mathrm{C}_{2} \mathrm{mpyr}\right][\mathrm{FSI}]$.

Figure $2 \mathrm{a}$ also highlights that increasing the volume fraction of PVDF in the composite has a suppressing effect on the enthalpy of the $\left[\mathrm{C}_{2}\right.$ mpyr][FSI] transition peaks. The intensity of the melting peak of $\left[\mathrm{C}_{2} \mathrm{mpyr}\right][\mathrm{FSI}]$ decreases gradually with increasing volume fraction of PVDF until the peak disappears in the composites when 50 vol\% PVDF and higher is added.

The first solid-solid transition of neat $\left[\mathrm{C}_{2} \mathrm{mpyr}\right][\mathrm{FSI}]$, occurring at $-72^{\circ} \mathrm{C}$, shows two overlapping peaks (Figure $2 b$ ). All the composite samples show this transition peak although they become increasingly distorted, and their onset temperatures are gradually shifted to higher temperatures with increasing volume fractions of PVDF. It is also observed that the addition of PVDF to the neat OIPC suppresses the first and second solid-solid transitions, as well as the melt phase of the OIPC. The distortion of the transition peaks of $\left[\mathrm{C}_{2} \mathrm{mpyr}\right][\mathrm{FSI}]$ with increasing volume fraction of PVDF suggests a degree of interaction between the OIPC and PVDF.

The interactions between OIPC and PVDF are also evidenced by the changes in the melting behaviour of PVDF during the heating scans. As shown in Figure 2c, two stages of low temperature melting (overlapping peaks from $135^{\circ} \mathrm{C}$ to $155^{\circ} \mathrm{C}$ ) are observed in the composites with 10 - 60 vol\% PVDF. These overlapping peaks are believed to be associated with the interphase layer formed between bulk PVDF and bulk OIPC. ${ }^{17}$ Because this interphase layer shows a lower melting point than bulk PVDF, we conclude that this layer is a PVDF-rich region mixed with OIPC cations and anions (see Figure $6 \mathrm{a}-\mathrm{c}$ for the schematic illustration). This low temperature shifting of PVDF in the [ $\left.\mathrm{C}_{2} \mathrm{mpy}\right][\mathrm{FSI}] / \mathrm{PVDF}$ composites also 
agrees well with PVDF/ionic liquid system reported by R. Mejri et al., ${ }^{27}$ which shows interactions similar to what is observed in this work. A third melting peak (around $160{ }^{\circ} \mathrm{C}$ ) is observed with PVDF volume fractions higher than 60 vol\%. This third melting peak is observed to be analogous to the melting peak of the bulk PVDF, which occurs at $164{ }^{\circ} \mathrm{C}$ (shown in a dotted blue line in Figure 2c). The melting peak of the bulk PVDF corresponds to that of the $\alpha$-phase, suggesting that the bulk PVDF is predominantly a-phase. Figure $2 \mathrm{c}$ also shows that the third PVDF melting peak only appears for the composites with high vol\% of PVDF, which suggests co-existing PVDF-rich interphase and $\alpha$-phase bulk PVDF. Table 1 shows the onset temperatures and enthalpy changes of the $\left[\mathrm{C}_{2} \mathrm{mpyr}\right][\mathrm{FSI}] / \mathrm{PVDF}$ composites. The gradual decrease in the enthalpies of the transition of $\left[\mathrm{C}_{2} \mathrm{mpyr}\right][\mathrm{FSI}]$ in the composites with increasing volume fractions of PVDF also suggests that the composite systems become more disordered compared to the neat OIPC.

Table 1: Onset temperatures and enthalpy changes of neat $\left[\mathrm{C}_{2} \mathrm{mpyr}\right][\mathrm{FSI}]$ and the $\left[\mathrm{C}_{2} \mathrm{mpyr}\right][\mathrm{FSI} / \mathrm{PVDF}$ composites. The enthalpy changes for the composite materials are reported as per gram of OIPC.

\begin{tabular}{|c|c|c|c|c|c|c|}
\hline \multirow{3}{*}{ vol\% of PVDF } & \multicolumn{6}{|c|}{ Onset $\mathrm{T}\left({ }^{\circ} \mathrm{C}\right) \pm 2{ }^{\circ} \mathrm{C}$ and $\Delta \mathrm{H}(\mathrm{J} / \mathrm{g}) \pm 5 \%$} \\
\hline & \multicolumn{2}{|l|}{ III to II } & \multicolumn{2}{|l|}{ II to I } & \multicolumn{2}{|c|}{$\begin{array}{l}\text { Melt } \\
{\left[\mathrm{C}_{2} \mathrm{mpyr}\right][\mathrm{FSI}]}\end{array}$} \\
\hline & $\mathrm{T} /{ }^{\circ} \mathrm{C}$ & $\begin{array}{l}\Delta \mathrm{H} \\
(\mathrm{J} / \mathrm{g} \text { OIPC })\end{array}$ & $\mathrm{T} /{ }^{\circ} \mathrm{C}$ & $\begin{array}{l}\Delta \mathrm{H} \\
(\mathrm{J} / \mathrm{g} \\
\text { OIPC) }\end{array}$ & $\mathrm{T} /{ }^{\circ} \mathrm{C}$ & $\begin{array}{l}\Delta \mathrm{H} \\
(\mathrm{J} / \mathrm{g} \\
\mathrm{OIPC})\end{array}$ \\
\hline 0 & -72 & 46.6 & -17 & 3.0 & 204 & 18.5 \\
\hline 10 & -72 & 44.8 & -17 & 2.9 & 203 & 16.3 \\
\hline 20 & -72 & 39.7 & -17 & 2.7 & 192 & 7.5 \\
\hline 30 & -71 & 39.6 & -16 & 2.6 & 189 & 5.9 \\
\hline 40 & -71 & 36.7 & -16 & 2.4 & - & - \\
\hline 50 & -71 & 33.4 & -16 & 2.1 & - & - \\
\hline 60 & -70 & 26.9 & -16 & 1.9 & - & - \\
\hline 70 & -70 & 17.3 & -14 & 1.2 & - & - \\
\hline 80 & -69 & 11.5 & -14 & 0.9 & - & - \\
\hline 90 & -69 & 4.0 & - & - & - & - \\
\hline
\end{tabular}




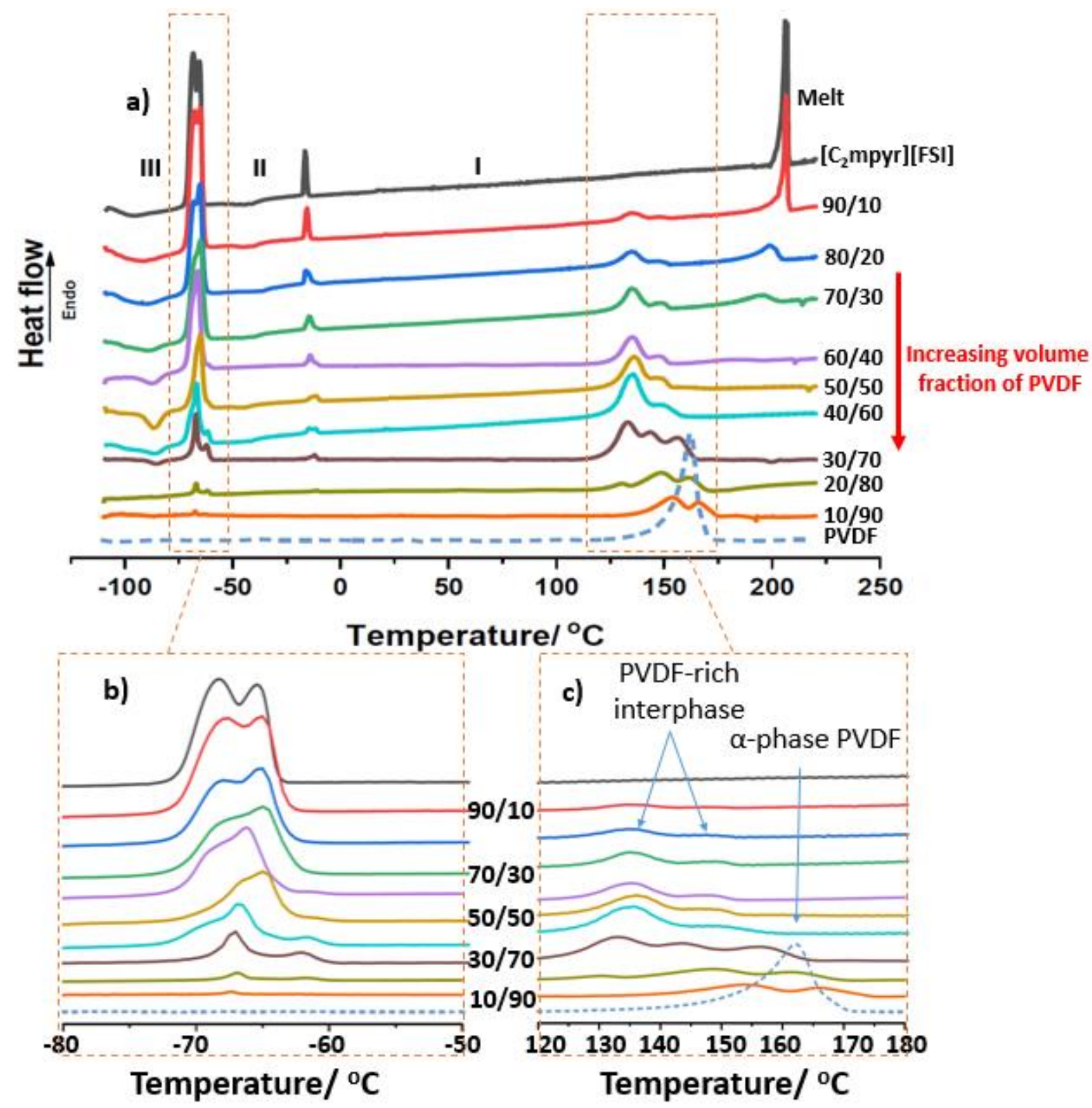

Figure 2: a. DSC traces of $\left[\mathrm{C}_{2} \mathrm{mpyr}\right][\mathrm{FSI}]$ and $\left[\mathrm{C}_{2} \mathrm{mpyr}\right][\mathrm{FSI}] /$ PVDF; b. transition from phase III/II; and c. transition from phase II/I

\subsection{Thermal behaviour of PS composites}

DSC studies were also conducted on $\left[\mathrm{C}_{2}\right.$ mpyr][FSI]/PS composites containing different volume fractions of PS (10 to 70 vol\%) to understand the interfacial interaction occurring between the OIPC and PS. The DSC heating traces of $\left[\mathrm{C}_{2} \mathrm{mpyr}\right][\mathrm{FSI}]$ and $\left[\mathrm{C}_{2} \mathrm{mpyr}\right][\mathrm{FSI}] / \mathrm{PS}$ composites are presented in Figure 3. The neat $\left[\mathrm{C}_{2} \mathrm{mpyr}\right][\mathrm{FSI}]$ shows three distinct peaks, while no new peaks are observed with the addition of PS. However, the glass transition for PS (which occurs just above $100^{\circ} \mathrm{C}$ ), is evident in the composite materials. Unlike the PVDF composites, increasing the volume fraction of PS in the composites does not suppress the 
size of the first and second solid-solid transition peaks, nor the melting temperature of the OIPC. Rather, the transition peaks of the $\left[\mathrm{C}_{2} \mathrm{mpyr}\right][\mathrm{FSI}] / \mathrm{PS}$ composites become sharper with an increasing volume fraction of PS, although their transition enthalpies do not change (as seen in table 2). This suggests different surface effects of PS nanoparticles on the phase behaviour of $\left[\mathrm{C}_{2} \mathrm{mpyr}\right][\mathrm{FSI}]$ compared to PVDF. This also indicates that, unlike PVDF nanoparticles, PS nanoparticles induce crystallographic ordering of $\left[\mathrm{C}_{2} \mathrm{mpyr}\right][\mathrm{FSI}]$ molecules rather than disorder observed in PVDF composites.

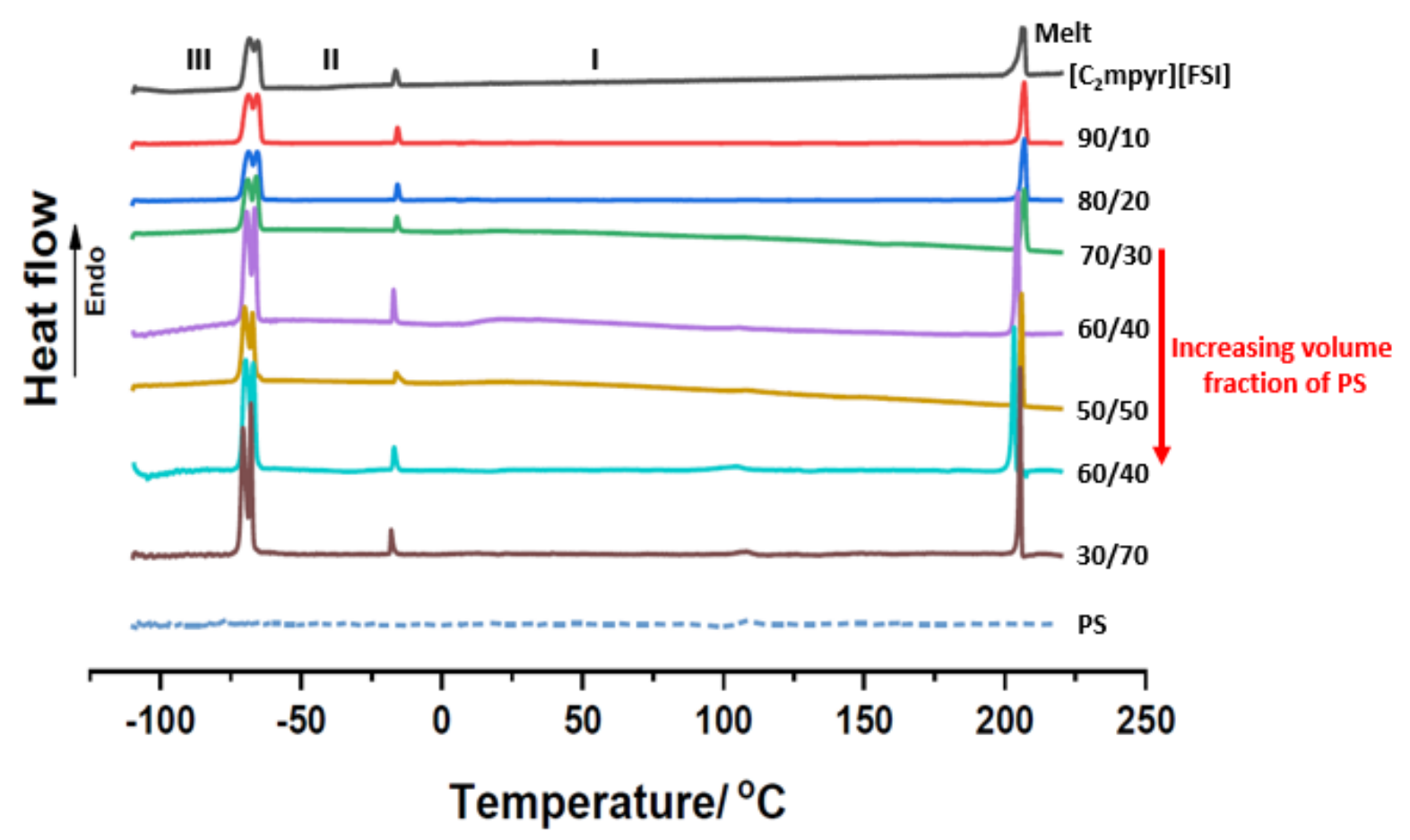

Figure 3: DSC heating traces of $\left[\mathrm{C}_{2} \mathrm{mpyr}\right][\mathrm{FSI}]$ and $\left[\mathrm{C}_{2} \mathrm{mpyr}\right][\mathrm{FSI}] / \mathrm{PS}$ composites with 10,20 , $30,40,50,60,70$ and 100 vol\% PS.

Table 2 presents the onset temperatures and the enthalpy changes occurring with increasing volume fractions of PS particles. The results show that no significant enthalpy changes are observed with the addition of PS particles, unlike the $\left[\mathrm{C}_{2}\right.$ mpyr][FSI]/PVDF composite system (Table 1). More interestingly, compared with the solid-solid transition peaks of bulk $\left[\mathrm{C}_{2} \mathrm{mpyr}\right][\mathrm{FSI}]$, a significant narrowing is observed in all composites containing PS nanoparticles (Figure 3). This shows that PS particles induce the $\left[\mathrm{C}_{2} \mathrm{mpyr}\right][\mathrm{FSI}]$ to form a more ordered structure. A graphical representation is presented in Figure 4 to illustrate the differences in the enthalpy changes of the various solid-solid transitions observed in both the $\left[\mathrm{C}_{2}\right.$ mpyr][FSI]/PVDF and $\left[\mathrm{C}_{2} \mathrm{mpyr}\right][\mathrm{FSI}] / \mathrm{PS}$ composites. It is clearly shown that the PVDF composites experience a decrease in the enthalpy change for the first and second solid-solid transitions as well as the melting peak of $\left[\mathrm{C}_{2} \mathrm{mpyr}\right][\mathrm{FSI}]$. This suggests that the composite 
systems become more disordered with the incorporation of PVDF nanoparticles. However, for the PS composites, there was no observed decrease of enthalpy for the various transition peaks suggesting that the ordering of the OIPC is not disrupted, neither is there evidence of a mixed-phase ordered structure in the PS systems.

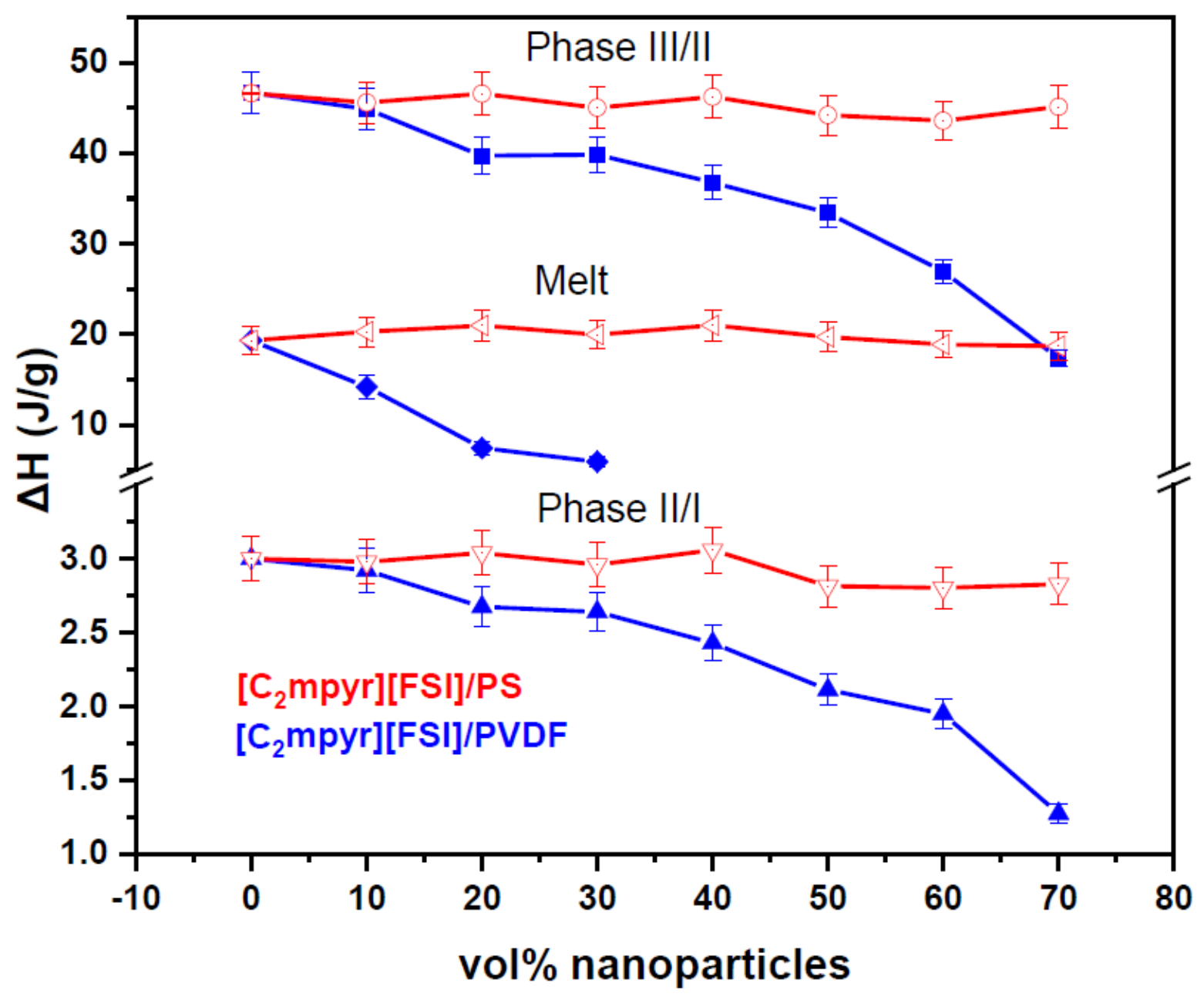

Figure 4: Comparison of the enthalpy changes of the two $\left[\mathrm{C}_{2} \mathrm{mpyr}\right][\mathrm{FSI}]$ based composite systems with increasing volume fraction of PVDF and PS nanoparticles. 
Table 2: Onset temperatures and enthalpy changes of the neat $\left[\mathrm{C}_{2} \mathrm{mpyr}\right][\mathrm{FSI}]$ and the $\left[\mathrm{C}_{2} \mathrm{mpyr}\right][\mathrm{FSI}] / \mathrm{PS}$ composites. The enthalpy changes for the composite materials are reported as per gram of OIPC.

\begin{tabular}{lllllll}
\hline \multirow{2}{*}{$\begin{array}{l}\text { vol\% of } \\
{\left[\mathrm{C}_{2} \mathrm{mpyr}\right][\mathrm{PSI}] / \mathrm{PS}}\end{array}$} & \multicolumn{5}{c}{ in } & \multicolumn{5}{c}{ Onset T $\left({ }^{\circ} \mathrm{C}\right) \pm 1{ }^{\circ} \mathrm{C}$ and $\Delta \mathrm{H}(\mathrm{J} / \mathrm{g}) \pm 5 \%$} \\
\cline { 2 - 7 } & $\mathrm{T} /{ }^{\circ} \mathrm{C}$ & $\begin{array}{l}\Delta \mathrm{H} \\
(\mathrm{J} / \mathrm{g} \text { oIPC })\end{array}$ & $\mathrm{T} /{ }^{\circ} \mathrm{C}$ & $\begin{array}{l}\Delta \mathrm{H} \\
(\mathrm{J} / \mathrm{g} \text { oIPC })\end{array}$ & $\mathrm{T} /{ }^{\circ} \mathrm{C}$ & $\begin{array}{l}\Delta \mathrm{H} \\
(\mathrm{J} / \mathrm{g} \text { oIPC })\end{array}$ \\
\hline 0 & -72 & 46.6 & -17 & 3.0 & 204 & 18.5 \\
10 & -71 & 45.5 & -17 & 2.9 & 204 & 20.3 \\
20 & -71 & 46.4 & -16 & 3.0 & 203 & 20.9 \\
30 & -71 & 45.0 & -16 & 2.9 & 204 & 19.9 \\
40 & -71 & 47.2 & -16 & 3.1 & 203 & 20.8 \\
50 & -71 & 44.2 & -16 & 2.8 & 204 & 19.7 \\
60 & -71 & 43.5 & -16 & 2.8 & 204 & 18.9 \\
70 & -71 & 46.6 & -17 & 2.8 & 204 & 18.7 \\
\hline
\end{tabular}

\subsection{The effects of nanoparticle surfaces on ion conductivities of OIPC composites}

Figure 5 compares the conductivity dependence of $\left[\mathrm{C}_{2} \mathrm{mpyr}\right][\mathrm{FSI}] / \mathrm{PVDF}$ and $\left[\mathrm{C}_{2} \mathrm{mpyr}\right][\mathrm{FSI}] / \mathrm{PS}$ composites as a function of temperature (Figure $5 \mathrm{a}$ ) and volume fraction of polymer nanoparticles (Figure $5 \mathrm{~b}$ ). The detailed conductivity data for $\left[\mathrm{C}_{2} \mathrm{mpyr}\right][\mathrm{FSI}] / \mathrm{PVDF}$ and $\left[\mathrm{C}_{2} \mathrm{mpyr}\right][\mathrm{FSI}] / \mathrm{PS}$ are presented in Figure S3. As demonstrated in Figure 5a, a general trend of increased conductivity with increasing temperature can be observed for all samples tested for samples. The absence of sudden changes is consistent with the DSC results since no solid-solid transitions are observed within the range of conductivity tested $\left(30-120^{\circ} \mathrm{C}\right)$.

Ionic conductivity of the composites increases with increasing PVDF volume fraction until 50 vol\% of PVDF. This increase in conductivity is attributed to the formation of a highly disordered OIPC interphase around the PVDF particles, which is an additional, different layer compared with PVDF-rich interphase suggested by DSC results from Figure 2c. However, beyond 50 vol\% of PVDF, the conductivity begins to drop. This is consistent with the DSC results obtained in Figure 2, where the disordered OIPC interphase is expected to disconnect with high PVDF volume fractions - on the other hand, increasing volume fractions of PS particles in the $\left[\mathrm{C}_{2} \mathrm{mpyr}\right][\mathrm{FSI}] / \mathrm{PS}$ composite results in decreased conductivity. There appears to be no significant change in the activation energy (Table S1) of the conductivity relative to the neat OIPC, which suggests that no new conduction pathways are formed other than the existing ones in the neat OIPC; i.e. no disordered OIPC interfacial layer exists in the composite with PS particles. Thus, without any new conductive pathways, the conductivity begins to decrease with higher volume fractions of PS, as the volume fraction of the OIPC decreases and the tortuosity increases. In contrast, the activation energies of $\left[\mathrm{C}_{2} \mathrm{mpyr}\right][\mathrm{FSI}] / \mathrm{PVDF}$ composites 
increase with increasing volume fraction of PVDF, suggesting that the conduction mechanism in the $\left[\mathrm{C}_{2}\right.$ mpyr][FSI]/PVDF composites differs from that of the neat $\left[\mathrm{C}_{2} \mathrm{mpyr}\right][\mathrm{FSI}$ (Table $\mathrm{S} 1$ ).
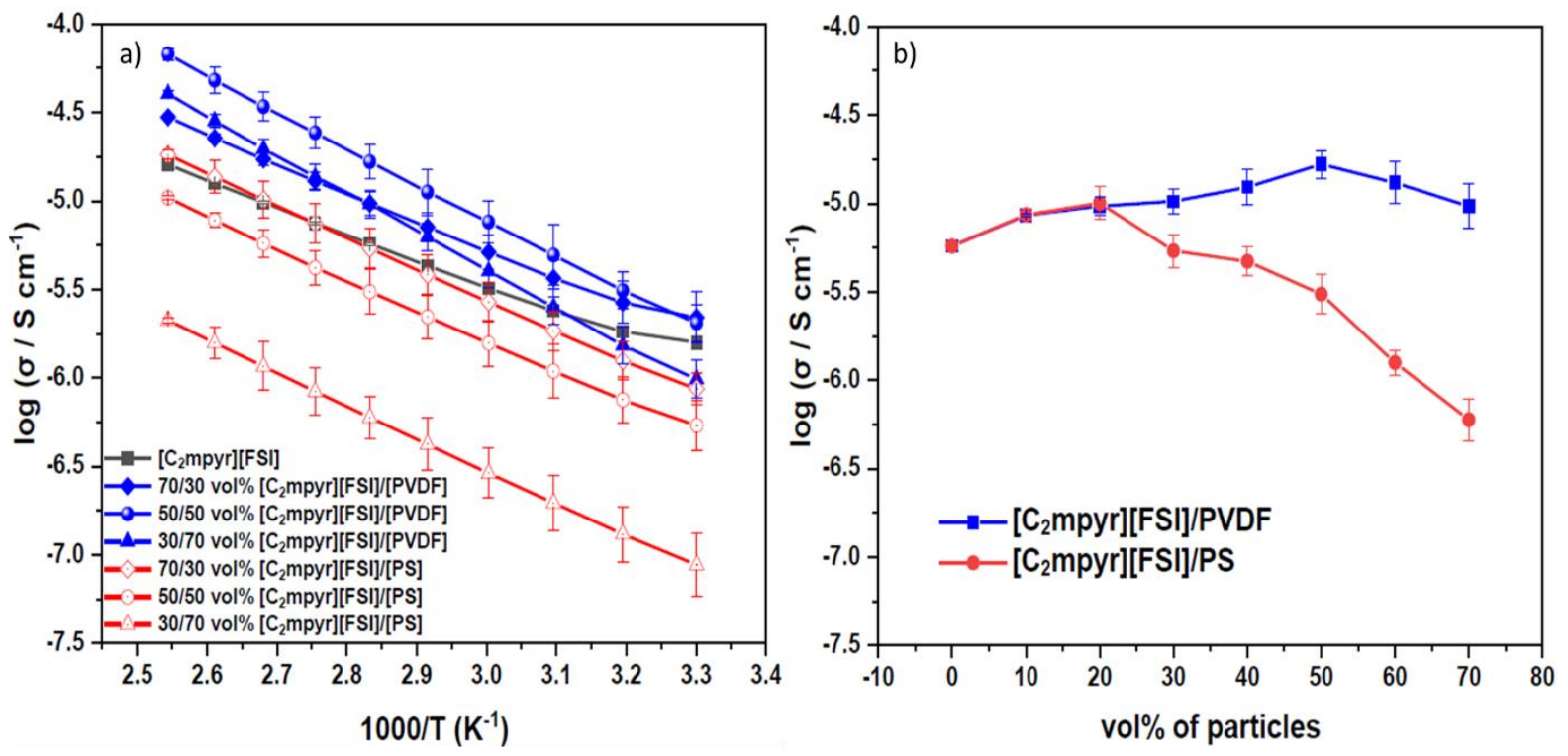

Figure 5: a. The temperature dependence of ionic conductivities for neat $\left[\mathrm{C}_{2} \mathrm{mpyr}\right][\mathrm{FSI}]$, and the $\left[\mathrm{C}_{2} \mathrm{mpyr}\right][\mathrm{FSI}] / \mathrm{PVDF}$ and $\left[\mathrm{C}_{2} \mathrm{mpyr}\right][\mathrm{FSI}] / \mathrm{PS}$ composites each at $70 / 30,50 / 50$, and $30 / 70$ vol\%; and b. Comparison of the conductivity of $\left[\mathrm{C}_{2} \mathrm{mpyr}\right][\mathrm{FSI}] / \mathrm{PVDF}$ and $\left[\mathrm{C}_{2} \mathrm{mpyr}\right][\mathrm{FSI}] / \mathrm{PS}$ at varying volume fractions (at $\left.80^{\circ} \mathrm{C}\right)$.

Figure $5 b$ compares the conductivity of $\left[\mathrm{C}_{2} \mathrm{mpyr}\right][\mathrm{FSI}] / \mathrm{PVDF}$ and $\left[\mathrm{C}_{2} \mathrm{mpyr}\right][\mathrm{FSI}] / \mathrm{PS}$ composites at $80^{\circ} \mathrm{C}$. Both systems show an initial increase in conductivity; however, after 20 vol\% of PS, the conductivity begins to decrease. As discussed above, it appears that increasing the PS volume fraction does not lead to the formation of a disordered OIPC interphase layer. This is due to the unfavourable interfacial interactions between $\left[\mathrm{C}_{2} \mathrm{mpyr}\right][\mathrm{FSI}]$ and $\mathrm{PS}$, which do not promote the formation of disordered OIPC zones. This is different from the $\left[\mathrm{C}_{2}\right.$ mpyr][FSI]/PVDF composites which form a disordered OIPC interphase, thus, forming a more conductive system compared to the neat $\left[\mathrm{C}_{2} \mathrm{mpyr}\right][\mathrm{FSI}]$.

The addition of low volume fractions of PS particles to $\left[\mathrm{C}_{2} \mathrm{mpyr}\right][\mathrm{FSI}]$ leads to an initial increase in conductivity (i.e. at 10 and 20 vol\% volume fractions) after which the conductivity begins to drop rapidly. The cause of the initial increase is reminiscent of the behaviour observed with the addition of inorganic oxide particles to both OIPC and polymer electrolytes. While we are not certain of the mechanism of enhancement here, such behaviour is ascribed to the formation of a space charge layer resulting in enhanced conductivity. ${ }^{28,29}$ In order to understand the exact mechanism of conductivity enhancement in this region, more systematic investigations are needed in the future. Beyond a volume fraction of 20 vol\%, the ordering 
effects of PS becomes dominant. Ordering of the OIPC has been observed to decrease ionic conductivity, as shown in previous literature. ${ }^{22}$ Consistent with DSC results, increasing PS volume fractions does not appear to create a disordered OIPC phase; thus, the presence of the non-conducting PS component leads to the observed decreased conductivity. Figure $6 \mathrm{~d}$ has been proposed as a model to explain the behaviour of PS particles in the OIPC.

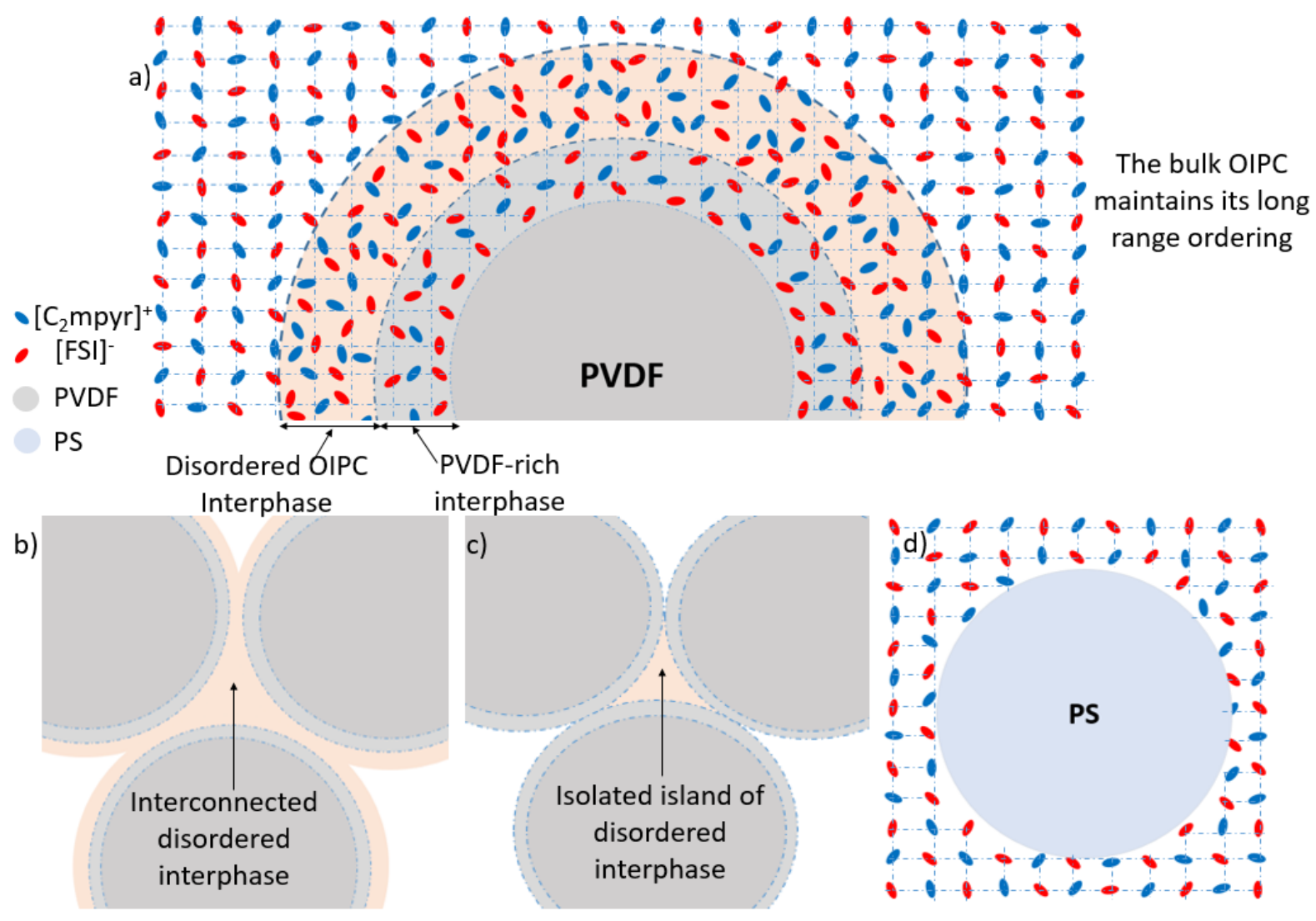

Figure 6: Schematics showing a) the origin of the interphase zones with PVDF volume fractions less than $50 \%$. The transition zones, which is between bulk PVDF and bulk OIPC, consists of disordered OIPC interphase and PVDF-rich interphase. b) the interconnection of the disordered OIPC interphase at 50\% volume fraction of PVDF; $c$ ) the isolation of the disordered OIPC interphase with PVDF volume fractions higher than 50\%; and d) the noninteracting nature of PS in the bulk OIPC, $\left[\mathrm{C}_{2} \mathrm{mpyr}\right][\mathrm{FSI}]$

Based on the DSC (Figure 2c) and conductivity (Figure S3a) results for [ $\left.\mathrm{C}_{2} \mathrm{mpyr}\right][\mathrm{FSI}] /$ PVDF composites, the structure models in Figure 6 (a-c) are proposed as the models for ion conduction in $\left[\mathrm{C}_{2} \mathrm{mpyr}\right][\mathrm{FSI}]$ composites with PVDF and PS nanoparticles. Specifically, for $\left[\mathrm{C}_{2}\right.$ mpyr][FSI]/PVDF composites, the low temperature shift of the PVDF melting peak (Figure 2c) suggests the formation of PVDF-rich interphase, which is composed of OIPC mobile ions 
and PVDF with crystalline domains (e.g. $\beta$-phase). The increase in conductivity of $\left[\mathrm{C}_{2}\right.$ mpyr] $[\mathrm{FSI}]$ /PVDF suggests the presence of a highly conductive phase, originating from the formation of disordered OIPC interphase. This disordered OIPC interphase provides new conductive pathways and allows increased ionic conductivities until the percolation threshold is exceeded (e.g. 50 vol\%). At 50 vol\% PVDF, there is just enough [ $\left.\mathrm{C}_{2} \mathrm{mpyr}\right][\mathrm{FSI}]$ to form percolating networks composed of a highly disordered OIPC interphase that facilitates ion conduction (Figure $6 \mathrm{~b}$ ); therefore the 50/50 vol\% [ $\left.\mathrm{C}_{2} \mathrm{mpyr}\right][\mathrm{FSI}] / \mathrm{PVDF}$ exhibits the highest conductivity of all the composites. Furthermore, based on the model proposed in Figure 6, the surface area or 'interphase' area of 50/50 vol\% [ $\left.\mathrm{C}_{2} \mathrm{mpyr}\right][\mathrm{FSI} / \mathrm{PVDF}$ is in a range of 4.7 to 4.9 $\mathrm{m}^{2}$ per gram of OIPC/PVDF composite. Also, the study of ageing and thermal effects on the sample (Figure S4 a-c) suggests that the disordered interphase formed is relatively stable since the properties of the samples do not change significantly with time and thermal treatment history.

The observed decrease in conductivity observed beyond 50 volume fractions of PVDF occurs because there is insufficient OIPC to form the highly disordered OIPC interphase. Also, the PVDF-rich zones begin to overlap at the expense of the disordered OIPC interphase because the particles begin to reach maximum packing closeness as proposed in the model and supported by SEM data (Figure $6 \mathrm{c}$ and Figure $\mathrm{S} 1 \mathrm{f}$ and $\mathrm{g}$ ). The PVDF-rich interphase is not expected to enhance mobility as much as the disordered OIPC interphase, so the overlap of PVDF-rich interphase layers creates isolated islands of disordered OIPC interphase within the interstitial sites de-percolating (or making discontinuous) the more conductive pathways, thus, leading to the observed drop in ionic conductivity (Figure 5b).

We also note that, according to the theory of random close packing (RCP) of spherical particles, randomly packed particles occupy $64 \%$ of the total volume of the sample. The percolation threshold of the PVDF particles is found to occur well below the volume fraction of nanoparticles, associated with a randomly close-packed network suggesting the presence of the interfacial interphase. The thickness of the disordered OIPC interphase was estimated to be about $15 \mathrm{~nm}$, as discussed in the supporting document.

\subsection{Ion mobilities of OIPC composites with different polymer nanoparticles}

Static solid-state NMR studies were conducted in an attempt to probe the ion mobility in the samples. This was done by studying the line shape and linewidths obtained for the samples. All the materials show a narrowing of peaks with increasing temperature, which indicates increasing cation and anion mobility in the samples with increasing temperature (Figure S5 and 6). Figure $7 \mathrm{a}$ shows a comparison of the ${ }^{1} \mathrm{H}$ spectra of neat $\left[\mathrm{C}_{2} \mathrm{mpyr}\right][\mathrm{FSI}], 50 / 50$ vol\% 
$\left[\mathrm{C}_{2} \mathrm{mpyr}\right]\left[\mathrm{FSI} / \mathrm{PVDF}\right.$ and $50 / 50$ vol\% $\left[\mathrm{C}_{2} \mathrm{mpyr}\right]\left[\mathrm{FSI} / \mathrm{PS}\right.$ at $70^{\circ} \mathrm{C}$, which is the highest operating temperature of the equipment. The neat material (Figure S5 a) shows a line shape with a broad component and a superimposed narrow component. The presence of the narrow component provides evidence of mobile cations in the neat material. The 50/50 vol\% $\left[\mathrm{C}_{2} \mathrm{mpy}\right][\mathrm{FSI}] / \mathrm{PS}$ composite has a line shape with only one component, which is slightly broader than that of the neat material. This suggests that the population of mobile cations in the PS composite is reduced. The 50/50 vol\% [ $\mathrm{C}_{2}$ mpyr][FSI]/PVDF composite shows the broadest component, and this is because the proton signal of PVDF and $\left[\mathrm{C}_{2} \mathrm{mpyr}\right][\mathrm{FSI}]$ will occur at the same position, so the overall peak of the composite results from a distribution of proton environments of $\left[\mathrm{C}_{2} \mathrm{mpyr}\right][\mathrm{FSI}]$ and PVDF. This observed broader signal also supports the notion of an interfacial region which contains both PVDF and OIPC; the bulk alpha phase PVDF, being less mobile, would not be visible in this spectrum as it would be a much broader line shape. A narrower component is also seen superimposed on the broad signal, which suggests that the PVDF composite contains some species with relatively higher mobility, indicative of the presence of a more conductive component formed by the interaction of the OIPC and the PVDF.

Figure $7 \mathrm{~b}$ shows a comparison of the ${ }^{19} \mathrm{~F}$ spectra of neat $\left[\mathrm{C}_{2} \mathrm{mpyr}\right][\mathrm{FSI}], 50 / 50$ vol\% $\left[\mathrm{C}_{2} \mathrm{mpyr}\right][\mathrm{FSI}] / \mathrm{PVDF}$ and $50 / 50$ vol\% $\left[\mathrm{C}_{2} \mathrm{mpyr}\right]\left[\mathrm{FSI} / \mathrm{PS}\right.$ at $70^{\circ} \mathrm{C}$. The neat material shows a line shape with only one component, whereas the 50/50 vol\% $\left[\mathrm{C}_{2} \mathrm{mpyr}\right][\mathrm{FSI}] / \mathrm{PS}$ shows a broader peak compared to the neat material. This would suggest that the anion mobility is reduced upon addition of PS. On the other hand, the $50 / 50$ vol\% $\left[\mathrm{C}_{2} \mathrm{mpyr}\right][\mathrm{FSI}] / \mathrm{PVDF}$ also shows a broader, more complex line shape which results from the distribution of anion environments in the different regions of the composite suggested in the schematic of Figure 6. As with the ${ }^{1} \mathrm{H}$ signals, some of the ${ }^{19} \mathrm{~F}$ signals are likely to include some signal from the fluorine atoms from PVDF in the interfacial OIPC/PVDF phase. This spectrum also shows a narrow superimposed component, indicative of some fraction of highly mobile anion species.

Based on the solid-state NMR results, it can be concluded that the addition of PVDF nanoparticles in $\left[\mathrm{C}_{2} \mathrm{mpyr}\right][\mathrm{FSI}$ can enhance the mobilities of both cations and anions of the OIPC, while decreased mobilities are observed for the PS nanocomposites. The NMR also supports the hypothesis of an additional 'ordered' PVDF/OIPC phase on the surface of the PVDF nanoparticles as suggested from the DSC data. 

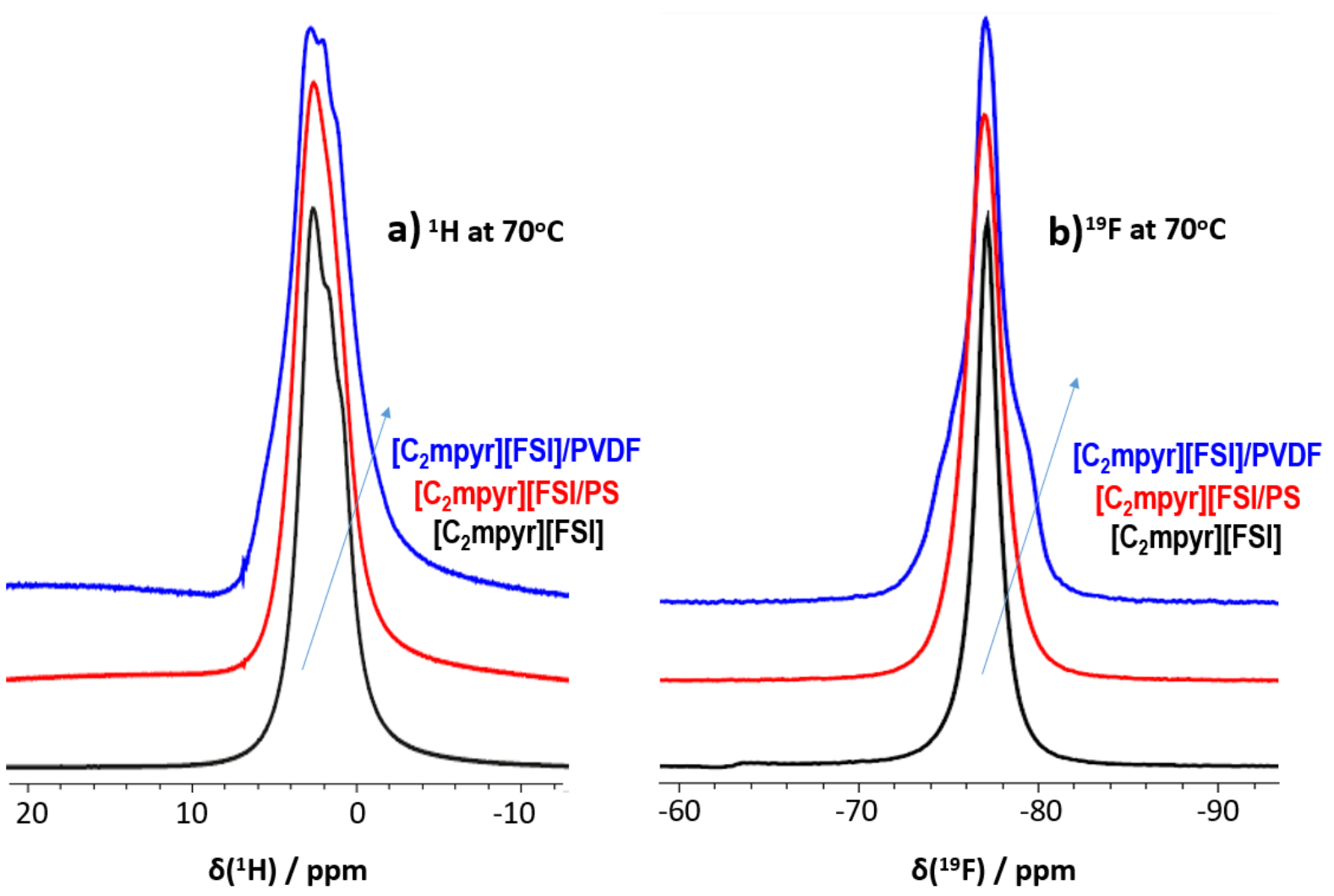

Figure 7: a. ${ }^{1} \mathrm{H}$ NMR spectra of $\left[\mathrm{C}_{2} \mathrm{mpyr}\right][\mathrm{FSI}], 50 / 50$ vol\% $\left[\mathrm{C}_{2} \mathrm{mpyr}\right][\mathrm{FSI}] / \mathrm{PVDF}$ and $50 / 50 \mathrm{vol} \%$ $\left[\mathrm{C}_{2} \mathrm{mpyr}\right][\mathrm{FSI}] / \mathrm{PS}$ at $70^{\circ} \mathrm{C}$ and b. ${ }^{19} \mathrm{~F}$ NMR spectra of $\left[\mathrm{C}_{2} \mathrm{mpyr}\right][\mathrm{FSI}], \quad 50 / 50$ vol\% $\left[\mathrm{C}_{2} \mathrm{mpyr}\right]\left[\mathrm{FSI} / \mathrm{PVDF}\right.$ and 50/50 vol\% $\left[\mathrm{C}_{2} \mathrm{mpyr}\right][\mathrm{FSI}] / \mathrm{PS}$ at $70^{\circ} \mathrm{C}$

\subsection{OIPC-polymer nanoparticle interactions}

FTIR analysis was employed to investigate the interactions of particular functional groups between different species, by studying the shifts in the major peaks that occur in the resultant system. PVDF is known to have at least five polymorphs, with the $\alpha, \beta, \gamma, \delta$ and $\varepsilon$ phases previously identified..$^{30}$ The most common of these polymorphs, i.e. $\alpha$ and $\gamma$ phases, are known to be non-polar while the other three are known to be polar ( $\beta, \delta$ and $\varepsilon$ phases). The unit cell arrangement of PVDF is dependent on which phase of PVDF is present. The $\alpha$-phase of PVDF with a TGTG' (trans-gauche-trans-gauche') chain conformation, has a monoclinic unit cell. The $\beta$ and $y$ phases both have orthorhombic unit cells with the $\beta$-phase having a TTTT (all trans) chain conformation while the $\delta$-phase has a TTTGTTTG' (trans-trans-trans-gauchetrans-trans-trans-gauche') chain conformation. The $\delta$-phase has a TTTGTTTG' (trans-transtrans-gauche-trans-trans-trans-gauche') chain conformation and the $\mathcal{\varepsilon}$-phase is also similar to the $\beta$ phase, but it is non-polar. ${ }^{31,32,33}$

The FTIR plots of PVDF, [ $\mathrm{C}_{2}$ mpyr][FSI] and [ $\mathrm{C}_{2}$ mpyr][FSI]/PVDF composites show the spectral changes that occur with increasing PVDF volume fractions (Figure 8a). From previous reports, the peaks located at $1480,1468,1453,1432,1406,1386,936,805 \mathrm{~cm}^{-1}$ are assigned to the 
alkyl groups of [ $\mathrm{C}_{2} \mathrm{mpyr}$ ] whiles 1051,1032 and $878 \mathrm{~cm}^{-1}$ peaks can be assigned to the pyrrolidinium ring of $\left[\mathrm{C}_{2} \mathrm{mpyr}\right] .^{34}$ The alkyl related modes of $\left[\mathrm{C}_{2} \mathrm{mpyr}\right]$ do not experience significant shifts except for those occurring at 1406 and $805 \mathrm{~cm}^{-1}$ which are shifted to lower and higher wavenumber values respectively. These shifts can be attributed to overlaps with PVDF peaks occurring in those same regions. The pyrrolidinium ring modes occurring at 1051 and $1032 \mathrm{~cm}^{-1}$ were not affected by the addition of PVDF, besides the peak at $878 \mathrm{~cm}^{-1}$, which was shifted to a lower wavenumber. The opposing shifts in the alkyl and pyrrolidinium ring modes on the addition of PVDF suggest a restructuring of the molecular orientation of the $\left[\mathrm{C}_{2} \mathrm{mpyr}\right][\mathrm{FSI}]$ into a lower energy mode. ${ }^{16}$

The peaks located at 1376, 1360, 1216, 1170, 1100, 825 and $741 \mathrm{~cm}^{-1}$ are assigned to the [FSI] anion. ${ }^{35}$ The $[\mathrm{FSI}]$ mode, occurring at $1360 \mathrm{~cm}^{-1}$, loses its intensity with increasing volume fractions of PVDF. On addition of PVDF, the [FSI] anion modes are generally shifted to higher wavenumbers, except for the peak at $1218 \mathrm{~cm}^{-1}$ which likely shifts to lower values as a result of overlap with the PVDF peak that is present in that same region.

The spectrum of PVDF shows characteristic $\beta$ peaks at 1279 and $509 \mathrm{~cm}^{-1}\left(\mathrm{CH}_{2}\right.$ rocking and $\mathrm{CF}_{2}$ stretching vibration respectively), and a peaks at $972 \mathrm{~cm}^{-1}\left(\mathrm{CH}_{2}\right.$ twisting), $795 \mathrm{~cm}^{-1}\left(\mathrm{CH}_{2}\right.$ rocking), $764 \mathrm{~cm}^{-1}$ ( $\mathrm{CF}_{2}$ bending), and $615 \mathrm{~cm}^{-1}\left(\mathrm{CH}_{2}\right.$ bending). ${ }^{31,36,37}$ This suggests the coexistence of both $\alpha$ and $\beta$ phases of PVDF. PVDF has no peak occurring at $1100 \mathrm{~cm}^{-1}$ so the shifts in the peaks of the [FSI] cannot be credited to overlaps, but rather interactions between the PVDF and [FSI] anion. The observed shifts to higher wavenumbers in the [FSI] bands can be as a result of hydrogen bonding interaction between the $\mathrm{C}-\mathrm{H}$ groups on PVDF and the $\mathrm{S}=\mathrm{O}$ groups on FSI. This is a much stronger interaction than a dipole-dipole interaction, which is needed to induce strong interfacial ordering (or a phase transition in the PVDF). 

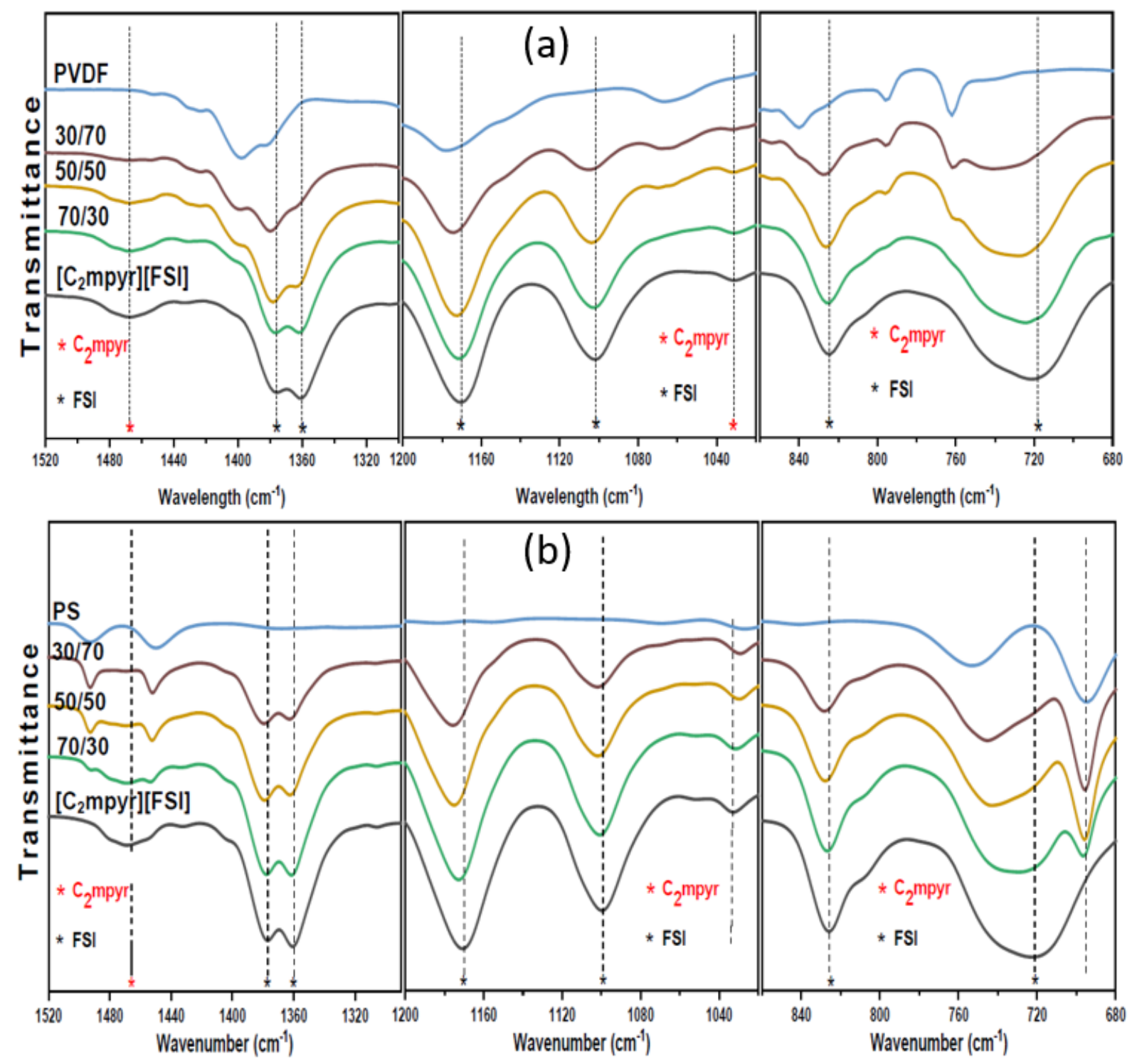

Figure 8: a. Comparison of the FTIR spectra of $\left[\mathrm{C}_{2} \mathrm{mpyr}\right][\mathrm{FSI}]$, the $\left[\mathrm{C}_{2} \mathrm{mpyr}\right][\mathrm{FSI}] / \mathrm{PVDF}$ composites at 70/30, 50/50, 70/30 vol\% and neat PVDF; b. Comparison of the FTIR spectra of $\left[\mathrm{C}_{2} \mathrm{mpyr}\right][\mathrm{FSI}], \mathrm{PS}$, and the $\left[\mathrm{C}_{2} \mathrm{mpyr}\right][\mathrm{FSI}] / \mathrm{PS}$ composites at $70 / 30,50 / 50,70 / 30 \mathrm{vol} \%$

Figure $8 \mathrm{~b}$ compares the FTIR plot of PS, [ $\left.\mathrm{C}_{2} \mathrm{mpyr}\right][\mathrm{FSI}]$ and the $\left[\mathrm{C}_{2} \mathrm{mpyr}\right][\mathrm{FSI} / \mathrm{PS}$ composites. The $[\mathrm{FSI}]$ vibrational modes of $\left[\mathrm{C}_{2} \mathrm{mpyr}\right][\mathrm{FSI}]$ are generally shifted to higher wavenumbers except for the peak occurring at $1216 \mathrm{~cm}^{-1}$, which is not affected. The peaks located at 1480 , $1468,1453,1432,1406,1386,936,805 \mathrm{~cm}^{-1}$ can be attributed to the alkyl groups of $\left[\mathrm{C}_{2} \mathrm{mpyr}\right]$. All the alkyl peaks remained unshifted upon addition of PS except for the peaks at $1452 \mathrm{~cm}^{-1}$ and $1098 \mathrm{~cm}^{-1}$, which were shifted to lower and higher wavenumbers respectively, as a result of the overlap with the PS peak occurring in the same region. The pyrrolidinium ring breathing 
mode at $1032 \mathrm{~cm}^{-1}$ was shifted to a lower wavenumber, but the ring deformation mode at 1051 $\mathrm{cm}^{-1}$ and the ring mode at $878 \mathrm{~cm}^{-1}$ were not shifted. The observed shifts suggest the presence of interactions between the OIPC and PS in these composites. The phenyl ring stretching vibrations of PS appear at 1602, 1494, 1450, 695 and $753 \mathrm{~cm}^{-1}$. The peaks occurring at 1602 , 1494 and $695 \mathrm{~cm}^{-1}$ do not experience any characteristic shifts whereas the peak occurring at $1450 \mathrm{~cm}^{-1}$ overlaps with the alkyl peak of $\left[\mathrm{C}_{2} \mathrm{mpyr}\right]$ at $1453 \mathrm{~cm}^{-1}$, which results in the observed shift. The change in the position of phenyl ring vibration occurring at $753 \mathrm{~cm}^{-1}$ to a lower wavenumber value can be attributed to the overlap with the PS peak occurring around the same region. The possible interaction observed in the PS system by FTIR seems conflict with the DSC and conductivity results, which needs further investigation.

Figure S7 presents a comparison of the FTIR peaks of 50 vol\% of PVDF and PS in the composite systems. Both systems show shifts in the FSI anion peaks. The most interesting of these shifts can be seen in the FSI peak occurring at $1100 \mathrm{~cm}^{-1}$ because there are no overlapping peaks from PVDF or PS. Although both PVDF and PS composites experience peak shifts, the peak shifts of PS based composites are higher compared to those of PVDF which suggests the interaction between $\left[\mathrm{C}_{2} \mathrm{mpyr}\right][\mathrm{FSI}] / \mathrm{PS}$ is stronger than that which exist between $\left[\mathrm{C}_{2} \mathrm{mpyr}\right][\mathrm{FSI}] / \mathrm{PVDF}$. A list of the various spectral features of $\left[\mathrm{C}_{2} \mathrm{mpyr}\right][\mathrm{FSI}]$ and how they are affected upon addition of 50 vol\% of PVDF or PS is presented in Table 3. 
Table 3: Assigned wavenumbers $\left(\mathrm{cm}^{-1}\right)$ for $\left[\mathrm{C}_{2} \mathrm{mpyr}\right][\mathrm{FSI}]$ and the effect on the peak position by the addition of 50 vol\% PVDF and PS

\begin{tabular}{|c|c|c|c|c|c|}
\hline \multirow[b]{2}{*}{ Structure } & \multicolumn{3}{|c|}{ Observed wave number values $\left(\mathrm{cm}^{-1}\right) \pm 1$} & \multirow[b]{2}{*}{ Band assignment } & \multirow[b]{2}{*}{ Ref. } \\
\hline & $\begin{array}{l}{\left[\mathrm{C}_{2} \mathrm{mpyr}\right][\mathrm{FSI}} \\
]\end{array}$ & $\begin{array}{l}{\left[\mathrm{C}_{2} \text { mpyr] }[\mathrm{FSI}] /\right.} \\
\text { PVDF }\end{array}$ & $\begin{array}{l}\left.\mathrm{C}_{2} \mathrm{mpyr}\right][\mathrm{FSI} \\
] / \mathrm{PS}\end{array}$ & & \\
\hline \multirow{7}{*}{ FSI } & 1376 & $1378(\uparrow)$ & $1379(\uparrow)$ & $\mathrm{Vas}_{\mathrm{as}} \mathrm{SO}_{2}$ & \multirow{7}{*}{35} \\
\hline & 1360 & $1363(\uparrow)$ & $1362(\uparrow)$ & $\mathrm{Vas}_{\mathrm{as}} \mathrm{SO}_{2}$ & \\
\hline & 1216 & $1213(\downarrow)$ & $1216(-)$ & $v_{\mathrm{s}} \mathrm{SO}_{2}$ & \\
\hline & 1170 & $1172(\uparrow)$ & $1175(\uparrow)$ & $v_{\mathrm{s}} \mathrm{SO}_{2}$ & \\
\hline & 1100 & $1104(\uparrow)$ & $1102(\uparrow)$ & & \\
\hline & 825 & $827(\uparrow)$ & $827(\uparrow)$ & $v_{\text {as }} S N S$ & \\
\hline & 741 & $746(\uparrow)$ & $745(\uparrow)$ & & \\
\hline \multirow{3}{*}{$\begin{array}{l}\text { Pyrrolidinium } \\
\text { ring }\end{array}$} & 1051 & $1051(-)$ & $1051(-)$ & $\delta($ ring $)$ & \multirow[t]{3}{*}{16} \\
\hline & 1032 & $1032(-)$ & $1029(\downarrow)$ & Ring breathing, & \\
\hline & 878 & $873(\downarrow)$ & $878(-)$ & $v(\mathrm{Et}-\mathrm{N}), v(\mathrm{Me}-\mathrm{N})$ & \\
\hline \multirow{9}{*}{ Alkyl groups } & 1480 & $1480(-)$ & $1480(-)$ & $\delta\left(\mathrm{CH}_{2}\right)$ (ring) & \multirow[t]{9}{*}{16} \\
\hline & 1468 & $1468(-)$ & $1468(-)$ & $\delta_{\mathrm{as}}\left(\mathrm{CH}_{3}\right)_{\mathrm{Me}}$ & \\
\hline & 1453 & $1453(-)$ & $1452(\downarrow)$ & $\delta(\mathrm{CH})_{2}$ & \\
\hline & 1432 & $1432(-)$ & $1432(-)$ & $\delta_{\mathrm{s}}\left(\mathrm{CH}_{3}\right)$ & \\
\hline & 1406 & $1403(\downarrow)$ & $1406(-)$ & $\delta_{\mathrm{s}}\left(\mathrm{CH}_{3}\right)_{\mathrm{Et}}+\delta_{\text {wag }}\left(\mathrm{CH}_{2}\right.$ & \\
\hline & 1386 & $1386(-)$ & $1386(-)$ & & \\
\hline & 1098 & $1098(-)$ & $1101(\uparrow)$ & $v_{\mathrm{as}}(\mathrm{C}-\mathrm{N})+\delta_{\mathrm{s}}\left(\mathrm{CH}_{3}\right)$ & \\
\hline & 936 & $936(-)$ & $936(-)$ & $\delta_{\text {rock }}\left(\mathrm{CH}_{3}\right)+\delta_{\text {rock }}(\mathrm{CH})$ & \\
\hline & 805 & $808(\uparrow)$ & $808(\uparrow)$ & $\begin{array}{l}v(\mathrm{C}-\mathrm{C})_{\mathrm{Et}} \\
\gamma(\mathrm{CH})\end{array}$ & \\
\hline
\end{tabular}

The direction of the band shift is designated by $(-),(\downarrow)$ and $(\uparrow)$, representing no shift, a shift to lower wavenumber and a shift to higher wavenumber, respectively. The abbreviations used in the band assignments represent the following: asymmetric stretch $=v_{\mathrm{as}}$; symmetric stretch $=$ $v_{\mathrm{s}}$; asymmetric deformation (bend) $=\delta_{\mathrm{as}}$; symmetric deformation (bend) $=\delta_{\mathrm{as}}$; out-of-plane deformation $=\gamma ; \mathrm{Et}=$ ethyl; $\mathrm{Me}=$ methyl

\section{Conclusion}

In this study, the influence of the interfacial interactions on changes in the phase behaviour and ion dynamics of $\left[\mathrm{C}_{2} \mathrm{mpyr}\right][\mathrm{FSI}]$ with respect to the addition of two different polymer nanoparticles (PVDF and PS) have been investigated. It is shown that the addition of different volume fractions of PVDF nanoparticles into the OIPC matrix disrupts ion ordering in the OIPC by forming a disordered OIPC interphase, which accounts for increased ionic conductivity (improved ion dynamics). Compared with neat OIPC, the ionic conductivity of the composites increases with increasing volume fraction of PVDF until 50 vol\% of PVDF, where the disordered OIPC interphase forms a percolating network of highly conducting disordered OIPC phase, beyond which ionic conductivity begins to drop. This observed decrease in conductivity was attributed to the overlap of the PVDF-rich zones, which are likely a phase 
containing both PVDF and OIPC. This results in isolated islands of the disordered OIPC phase, thereby decreasing ionic conductivity. NMR results show that in the $\left[\mathrm{C}_{2}\right.$ mpyr][FSI]/PVDF composite, a fraction of anions and cations have higher mobility compared to the neat $\left[\mathrm{C}_{2} \mathrm{mpyr}\right][\mathrm{FSI}]$. FTIR results suggest the formation of hydrogen bonds between the $\mathrm{H}$ of PVDF and the $\mathrm{SO}_{2}$ groups of $\left[\mathrm{C}_{2} \mathrm{mpyr}\right][\mathrm{FSI}]$. This strong interaction between PVDF and $\left[\mathrm{C}_{2} \mathrm{mpyr}\right][\mathrm{FSI}]$ could be the driving force to form miscible new interphase as well as a disordered OIPC interphase. SEM studies showed that PVDF particles are evenly distributed in the OIPC matrix, which affirms the interaction between the OIPC and PVDF particles.

On the other hand, the addition of PS nanoparticles to $\left[\mathrm{C}_{2} \mathrm{mpyr}\right][\mathrm{FSI}]$ does not disrupt the ordering of the OIPC matrix. From the DSC results, all the peak positions of the neat OIPC are maintained, but the peaks become narrower with increasing volume fractions of PS, suggesting that the ordering of the OIPC is not disrupted. No new phases become evident with the addition of PS. The ionic conductivity of the composites slightly increases with low volume fractions of PS which are yet to be fully understood but are reminiscent of space charge effects previously reported in electrolytes with inorganic fillers. However, the conductivity quickly drops with increasing volume fraction of PS nanoparticles. The sudden drop in conductivity stems from the aggregated, non-interacting PS particles. The presence of these aggregated phases, as shown by SEM, stems from the non-wetting nature of PS and it increases tortuosity in the $\left[\mathrm{C}_{2} \mathrm{mpyr}\right][\mathrm{FSI}] / P S$ system. The different effects of PVDF and PS on the phase behaviour of $\left[\mathrm{C}_{2} \mathrm{mpyr}\right][\mathrm{FSI}]$ highlight the importance of the interfacial effects in OIPC/polymer composites and provide insight for the design of highly conducting OIPC polymer nanoparticle composites.

\section{Acknowledgements}

The authors would like to thank Dr Wesley A. Henderson for his valuable discussion and the US Army Research Office (ARO) for financial support (W911NF1710560). The Australian Research Council (ARC) is acknowledged for support through the Australian Postgraduate Awards and Deakin University postgraduate research scholarships. L. P. received funding from the European Union's Horizon 2020 research and innovation programme under the Marie Skłodowska-Curie grant agreement No. 797295. Dr Ruhamah Yunis is also acknowledged for her help with plastic crystal synthesis. 


\section{References}

1. Jacobson, M. Z. \& Delucchi, M. A. Providing all global energy with wind, water, and solar power, Part I: Technologies, energy resources, quantities and areas of infrastructure, and materials. Energy Policy 39, 1154-1169 (2011).

2. Pringle, J. M. Recent progress in the development and use of organic ionic plastic crystal electrolytes. Phys.Chem. Chem. Phys 15, 1339-1351 (2013).

3. Jin, L. et al. Environmental Science lithium batteries †. Energy Environ. Sci. 7, 33523361 (2014).

4. Zhou, Z. Bin \& Matsumoto, H. Lithium-doped, organic ionic plastic crystal electrolytes exhibiting high ambient-temperature conductivities. Electrochem. commun. 9, 10171022 (2007).

5. Howlett, P. C. et al. On the use of organic ionic plastic crystals in all solid-state lithium metal batteries. Solid State Ionics 204-205, 73-79 (2011).

6. Pringle, J. M., Shekibi, Y., MacFarlane, D. R. \& Forsyth, M. The influence of different nanoparticles on a range of organic ionic plastic crystals. Electrochim. Acta 55, 88478854 (2010).

7. Pringle, J. M., Howlett, P. C., Macfarlane, D. R. \& Forsyth, M. Organic ionic plastic crystals : recent advances. 2056-2062 (2010). doi:10.1039/b920406g

8. TImmermans, J. PLASTIC CRYSTALS : A HISTORICAL. 18, 1-8 (1961).

9. Annat, G., Adebahr, J., Mckinnon, I. R., Macfarlane, D. R. \& Forsyth, M. Plastic crystal behaviour in tetraethylammonium dicyanamide. 178, 1065-1071 (2007).

10. Cardini, G., Righini, R. \& Califano, S. Computer simulation of the dynamics of the plastic phase of succinonitrile. J. Chem. Phys. (1991). doi:10.1063/1.461418

11. Macfarlane, D. R., Huang, J. \& Forsyth, M. Lithium-doped plastic crystal electrolytes exhibiting fast ion conduction for secondary batteries. Nature 402, 792-794 (1999).

12. Abouimrane, A., Abu-lebdeh, Y., Alarco, P. \& Armand, M. Plastic Crystal-Lithium Batteries : An Effective Ambient Temperature All-Solid-State Power Source. 10281031 (2004). doi:10.1149/1.1759971

13. Howlett, P. C., Shekibi, Y., MacFarlane, D. R. \& Forsyth, M. Li-metal symmetrical cell studies using ionic organic plastic crystal electrolyte. Adv. Eng. Mater. 11, 1044-1048 (2009). 
14. Makhlooghiazad, F. et al. Mixed Phase Solid-State Plastic Crystal Electrolytes Based on a Phosphonium Cation for Sodium Devices. Adv. Energy Mater. 7, (2017).

15. Makhlooghiazad, F. et al. Phosphonium plastic crystal salt alloyed with a sodium salt as a solid-state electrolyte for sodium devices: phase behaviour and electrochemical performance. J. Mater. Chem. A 5, 5770-5780 (2017).

16. Iranipour, N. et al. Ionic transport through a composite structure of $\mathrm{N}$-ethyl- $\mathrm{N}$ methylpyrrolidinium tetra fl uoroborate polymer nano fi bres †. J. Mater. Chem. A Mater. energy Sustain. 3, 6038-6052 (2015).

17. Wang, X. et al. Organic lonic Plastic Crystal-Based Composite Electrolyte with Surface Enhanced Ion Transport and Its Use in All-Solid-State Lithium Batteries. Adv. Mater. Technol. 2, 1700046 (2017).

18. Masahiro Yoshizawa-Fujita, Erina Kishi, Mitsutake Suematsu, Toshihiro Takekawa, and M. R. A Plastic Electrolyte Material in a Highly Desirable Temperature Range: NThe Chemical Society of Japan. Chem. Lett. (2016). doi:10.1246/cl.140833

19. Zhou, Y. et al. N-ethyl-N-methylpyrrolidinium bis(fluorosulfonyl)imide-electrospun polyvinylidene fluoride composite electrolytes: Characterization and lithium cell studies. Phys. Chem. Chem. Phys. 19, 2225-2234 (2017).

20. Zhou, Y. et al. Ternary lithium-salt organic ionic plastic crystal polymer composite electrolytes for high voltage, all-solid-state batteries. Energy Storage Mater. 0-1 (2018). doi:10.1016/j.ensm.2018.07.017

21. Díaz, M. et al. Protic plastic crystal/PVDF composite membranes for Proton Exchange Membrane Fuel Cells under non-humidified conditions. Electrochim. Acta 247, 970976 (2017).

22. Rao, J. et al. Influence of Electrospun Poly(vinylidene difluoride) Nanofiber Matrix on the Ion Dynamics of a Protic Organic Ionic Plastic Crystal. J. Phys. Chem. C 122, 14546-14553 (2018).

23. Dean, P. M. et al. Structural characterization of novel ionic salts incorporating trihalide anions. Aust. J. Chem. 62, 334-340 (2009).

24. Fdz De Anastro, A. et al. Poly(ionic liquid) iongels for all-solid rechargeable zinc/PEDOT batteries. Electrochim. Acta 278, 271-278 (2018).

25. Rainò, G. et al. Underestimated Effect of a Polymer Matrix on the Light Emission of Single CsPbBr3 Nanocrystals. Nano Lett. 19, 3648-3653 (2019). 
26. Zhou, Y. et al. N-ethyl-N-methylpyrrolidinium bis(fluorosulfonyl)imide-electrospun polyvinylidene fluoride composite electrolytes: Characterization and lithium cell studies. Phys. Chem. Chem. Phys. 19, 2225-2234 (2017).

27. Mejri, R. et al. Effect of ionic liquid anion and cation on the physico-chemical properties of poly(vinylidene fluoride)/ionic liquid blends. Eur. Polym. J. 71, 304-313 (2015).

28. Maier, J. Ionic conduction in space charge regions. Progress in Solid State Chemistry 23, 171-263 (1995).

29. Shekibi, Y., Gray-weale, A., Macfarlane, D. R., Hill, A. J. \& Forsyth, M. Nanoparticle Enhanced Conductivity in Organic Ionic Plastic Crystals : Space Charge versus Strain Induced Defect Mechanism. 11463-11468 (2007). doi:10.1021/jp071631j

30. El Achaby, M., Arrakhiz, F. Z., Vaudreuil, S., Essassi, E. M. \& Qaiss, A. Piezoelectric $\beta$-polymorph formation and properties enhancement in graphene oxide - PVDF nanocomposite films. Appl. Surf. Sci. 258, 7668-7677 (2012).

31. Ahn, Y. et al. Enhanced piezoelectric properties of electrospun poly(vinylidene fluoride)/multiwalled carbon nanotube composites due to high $\beta$-phase formation in poly(vinylidene fluoride). J. Phys. Chem. C 117, 11791-11799 (2013).

32. Huang, R., Wang, G., Guo, S., Wang, K. \& Fu, Q. Crystallographic features of poly(vinylidene fluoride) film upon an attractive substrate of KBr. Phys. Chem. Chem. Phys. 19, 27828-27838 (2017).

33. Bohle, M. \& Bolton, K. using density functional theory. 12929-12939 (2014). doi:10.1039/c4cp01012d

34. Li, X., Zhang, Z., Li, S., Yang, K. \& Yang, L. Polymeric ionic liquid-ionic plastic crystal all-solid-state electrolytes for wide operating temperature range lithium metal batteries. J. Mater. Chem. A 5, 21362-21369 (2017).

35. Huang, J. \& Hollenkamp, A. F. Thermal behavior of ionic liquids containing the FSI anion and the Li + cation. J. Phys. Chem. C 114, 21840-21847 (2010).

36. Ruan, L. et al. Properties and applications of the $\beta$ phase poly(vinylidene fluoride). Polymers (Basel). 10, 1-27 (2018).

37. Kim, G. H., Hong, M. \& Seo, Y. Piezoelectric properties of poly ( vinylidene fluoride ) and carbon nanotube blends : b -phase development. 10506-10512 (2009). doi:10.1039/b912801h 
